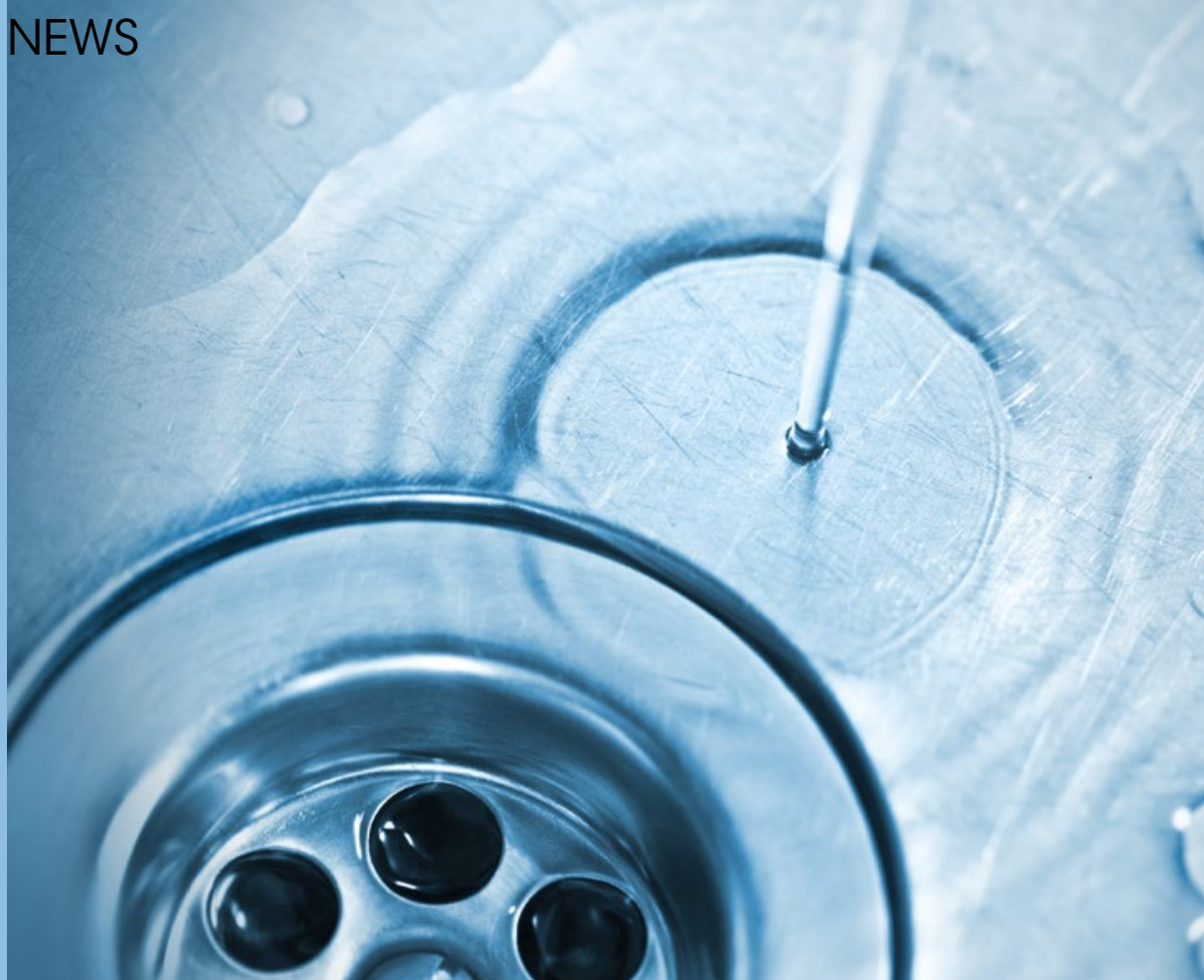

\title{
TELL YOUR PATIENTS TO TURN OFF THE TAPS
}

A dental hygienist and leading educationalist is calling on dental teams to help change the way the world's population cleans its teeth.

Tim Ives, co-founder of the digital and eco-friendly online O'Hehir University (OHU), wants everyone in dentistry to help make a difference to global climate change by asking patients to turn off taps when brushing their teeth in a bid to minimalise the negative effect on the environment.

He is urging dental professionals to play their part in energy reduction and water preservation.

Tim said: 'World leaders have been meeting to reach an agreement to reduce carbon emissions in order to decrease the heating of our planet and the subsequent dangers that would result, such as global sea level rise.

'If all the people in the world started to make this small change of turning the tap off, we would already be well on the way to meeting the target for the first year in energy consumption.'

Tim said that he has insight into 'how we can engender a small simple change that will make an enormous difference to our planet' and wants everyone to ask families, friends, colleagues and patients to turn off the tap when brushing teeth.

He said: 'Some people may think this is such a small thing, and that it will have very little impact compared to the effect of changes in transport and industry, but it is all about helping to meet the targets set by our leaders, who will be setting goals for reductions in energy consumption throughout the forthcoming years.'

In order to demonstrate this, he offers some mathematical approximations based on brushing teeth twice a day with the water running:

The tap would run for two minutes each cleaning and the water flow would typically be 2.5 gallons per minute. Annually this would equal: 2 minutes $x$ 2.5 gallons $\mathrm{x} 365$ days $=1,825$ gallons of water per year per person.

If this was reduced to ten seconds twice a day in order to wet the brush and rinse at the end - although we know it is better not to rinse in order to maximise fluoride - each person would use 182.5 gallons of water per year and make a $90 \%$ saving.

Tim added: 'This is also an opportunity to spread the "spit don't rinse" message at the same time, impacting on caries reduction.

The 2008 Climate Change Act committed the government to ensure net UK carbon emissions were $80 \%$ below 1990 levels by 2050. In June 2019, this was raised to $100 \%$ - effectively making the UK carbon neutral by 2050 .

The Centre for Sustainable Healthcare suggests there are four principles of sustainable dentistry: prevention, low carbon alternatives, lean pathways and patient empowerment and self-care.

\section{A CELEBRATION OF CHRIS KETTLER}

The Orthodontic National Group (ONG) has been celebrating the life and legacy of specialist practitioner and former President Chris

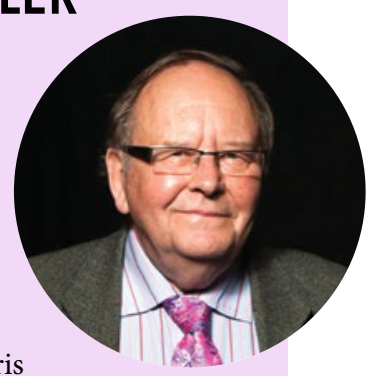

Kettler, who died suddenly

in November.

Chris was a passionate advocate for orthodontic therapists and dental nurses and did what he could to see their contribution to patient care expanded and recognised.

In the early years of his career there were five different societies representing different aspects of the orthodontic specialty. Chris had three aims:

- The unification of the five societies to form the British Orthodontic Society

- The creation of a specialist list for orthodontists

- The creation of the role of orthodontic therapist (OT).

All were achieved in his lifetime, in a significant part due to his energy and commitment. Among other roles, he served on the GDC Working Group for the OT Curriculum. From 2009-2011 he was President of ONG.

Fiona Grist, a former vice-chair of ONG, was a friend of Chris and attended his funeral. She said of him: 'He was a wonderful champion for orthodontic dental nurses and he encouraged the team approach by example, taking and encouraging his staff to attend British Orthodontic Conference and study days. He was keen to develop the role of the nurse both in the area of extended duties but also in the pathway leading to orthodontic therapy.

'When the BOS was exploring the possibilities of ONG becoming a group affiliated to the BOS Chris represented the Society and when a mutually amicable solution was reached it was down in no small part to his presence. His work ethic was huge and this was mirrored in his achievements.

Chris was awarded an MBE in 2011 for service to the profession - the first specialist orthodontist practitioner to be recognised as such. 